\title{
Dynamic Prediction of Financial Distress Based on Kalman Filtering
}

\author{
Qian Zhuang and Lianghua Chen \\ School of Economics and Management, Southeast University, Nanjing, Jiangsu 211189, China \\ Correspondence should be addressed to Qian Zhuang; zhuangseu@163.com
}

Received 24 April 2014; Revised 25 June 2014; Accepted 25 June 2014; Published 10 July 2014

Academic Editor: Zhengqiu Zhang

Copyright ( 2014 Q. Zhuang and L. Chen. This is an open access article distributed under the Creative Commons Attribution License, which permits unrestricted use, distribution, and reproduction in any medium, provided the original work is properly cited.

\begin{abstract}
The widely used discriminant models currently for financial distress prediction have deficiencies in dynamics. Based on the dynamic nature of corporate financial distress, dynamic prediction models consisting of a process model and a discriminant model, which are used to describe the dynamic process and discriminant rules of financial distress, respectively, is established. The operation of the dynamic prediction is achieved by Kalman filtering algorithm. And a general $n$-step-ahead prediction algorithm based on Kalman filtering is deduced in order for prospective prediction. An empirical study for China's manufacturing industry has been conducted and the results have proved the accuracy and advance of predicting financial distress in such case.
\end{abstract}

\section{Introduction}

Research on financial distress prediction (FDP) is an important area of corporate finance. Early prediction methods are univariate analysis (UA), multiple discriminant analysis (MDA), logistic model, probit model, and so on [1-5]. With the development of computer technology, some new methods based on artificial intelligence technology with distributed computing capabilities that can deal with problems of nonlinear systems are widely introduced into the field of financial distress prediction. These methods include neural network $(\mathrm{NN})$, genetic algorithm $(\mathrm{GA})$, rough set theory (RST), casebased reasoning (CBR), and support vector machine (SVM) [6-14]. Each model established for financial distress prediction, whether based on statistical methods or artificial intelligence methods, has advantages and disadvantages under different conditions. Take the most widely used multiple discriminant analysis (MDA) and backpropagation neural network (BPNN), for example. MDA has the advantage of simplicity and good interpretation, but the deficiency in its application limited by strict assumptions that sometimes cannot be satisfied. Besides, MDA is a static discriminant model $[2,3,6,15,16]$. For the application of BPNN, it does not need any probability distribution assumption. BPNN is considered as an effective tool of pattern recognition for nonlinear systems. So many researchers have tried to apply triple BPNN in financial distress prediction, using the nonlinear pattern recognition capability of BPNN for classification of different financial state $[7,8,15]$.

The prediction was often achieved through a crosssectional analysis at different time points. That is, the sample data of period $t-1, t-2, \ldots$ before financial distress is studied by BPNN, respectively, and the features are extracted, based on what the judgment for the financial state of next new period is made [16-18]. This treatment is a relatively complete cross-sectional analysis. But the conclusions on discrimination among different time points are lack of logistic links. So this prediction is not completely dynamic. Furthermore, BPNN is a static neural network even when directly used in time-series prediction. (Neural networks can be divided into static or dynamic neural networks based on whether they contain feedback loops or delay. BPNN is a backpropagation network without feedback and belongs to static neural networks.) There are some inherent problems such as overfitting. For example, the fitting error of training data has reduced, but the prediction error has increased at the same time. Even if the data is normalized, the effect is not satisfactory when the testing data is not sufficient $[13,16,19,20]$.

Actually, corporate financial distress is a gradual and cumulative process, which is developed from a healthy state. 
The mutation is often the result at which the gradual change and cumulation have reached the critical condition. It is neither reasonable nor logical if only the cross-sectional data at the time point prior to the occurrence of financial distress is used to make a determination for the corporate future state. Two aspects should be taken into account at least when conducting the research on financial distress prediction: firstly, the alternative data for prediction should contain all of the historical information; secondly, the prediction method is dynamically designed for financial distress characterized by cumulative variation [21-23]. However, the current discriminant models have some deficiencies in dynamic prediction. Also there is a problem of massive data processing. This paper attempts to make a dynamic improvement on prediction methods for financial distress based on Kalman filtering algorithm in order to solve the above problems.

The rest of this paper is organized as follows. dynamic prediction models consisting of a process model and a discriminant model based on Kalman filtering algorithm is described in Section 2. Then a whole process of dynamic prediction for corporate financial distress is elaborated in Section 3. Section 4 presents empirical analysis for China's manufacturing industry. Section 5 draws conclusions and discusses future research.

\section{Dynamic Prediction Models Based on Kalman Filtering Algorithm}

Based on the state-space method, we establish two models that are used to describe the dynamic process and discriminant rules of financial distress, respectively, that is, a process model and a discriminant model. These two models collectively are called dynamic prediction models for financial distress. A process model is used to describe the dynamic process of development of the financial state. We define the financial state as a set of vectors, which summarizes all of the information necessary about the past behavior of the company except for the external effects of the inputs, which can uniquely describe the behavior of the company in the near future [24]. The financial state of a company often can not be observed directly, but only some signal indicators associated with the financial state can be observed. So we establish a discriminant model which is used to describe the correlation between the financial state and the signal indicators. The discriminant model can be a recursive form of any statistical model or artificial intelligence model theoretically. At first we take the linear model which is simple and intuitive as an example and establish dynamic prediction models for financial distress, as

$$
\begin{gathered}
X_{t}=A_{t \mid t-1} X_{t-1}+W_{t-1}, \\
Z_{t}=H_{t} X_{t}+V_{t},
\end{gathered}
$$

where $X_{t}$ is the financial state of a company in period $t ; Z_{t}$ is the signal indicators of the company in period $t ; W_{t-1}$ is the process noise of the financial state in period $t-1 ; V_{t}$ is the observation noise of the signal indicators in period $t ; A_{t \mid t-1}$ is used to describe the dynamic process of the financial state transferring from period $t-1$ to $t ; H_{t}$ is used to describe the mathematical relations between the financial state and the signal indicators in period $t$. Equation (1) is a process model; and (2) is a discriminant model.

Assume that the process noise and the observation noise are Gaussian white noises, which are mutually independent and normally distributed; that is,

$$
\begin{gathered}
E\left[W_{t}\right]=0, \quad E\left[W_{t} W_{j}^{T}\right]=Q_{t} \delta_{t j}, \\
E\left[V_{t}\right]=0, \quad E\left[V_{t} V_{j}^{T}\right]=R_{t} \delta_{t j}, \\
E\left[W_{t} V_{j}^{T}\right]=0,
\end{gathered}
$$

where $Q_{t}$ is a $p \times p$-dimensional symmetric nonnegative definite covariance matrix of process noise $W_{t} ; R_{t}$ is a $m \times m$ dimensional symmetric positive definite covariance matrix of observation noise $V_{t} ; \delta_{t j}$ is Kronecker- $\delta$ function.

The above equations can be solved by Kalman filtering algorithm. The Kalman filter is named after Rudolph E. Kalman, who in 1960 published his famous paper describing a recursive solution to the discrete data linear filtering problem. The Kalman filter is essentially a set of mathematical equations that implement a predictor-corrector type estimator that is optimal in the sense that it minimizes the estimated error covariance when some presumed conditions are met $[25,26]$. Kalman filter is widely used for its relative simplicity and robust nature. Rarely do the conditions necessary for optimality actually exist, and yet the filter apparently works well for many applications in spite of this situation. The Kalman filtering process consists of five steps [27, 28].

The first step is to compute the one-step prediction of the state $\widehat{X}_{t \mid t-1}$ under the conditions of known $\widehat{X}_{t-1 \mid t-1}$ which is the optimal estimation of the state at time $t-1$ :

$$
\widehat{X}_{t \mid t-1}=A_{t \mid t-1} \widehat{X}_{t-1 \mid t-1} \text {. }
$$

The second step is to compute the error covariance matrix $P_{t \mid t-1}$ for one-step prediction

$$
P_{t \mid t-1}=A_{t \mid t-1} P_{t-1 \mid t-1} A_{t \mid t-1}^{T}+Q_{t-1} .
$$

The third step is to compute the Kalman gain $K_{t}$, which is a blending factor that is used to adjust the discrepancy between the predicted observation $H_{t} \widehat{X}_{t \mid t-1}$ and the actual observation $Z_{t}$, in order to obtain the optimal estimation $\widehat{X}_{t \mid t}$ closer to the actual state

$$
K_{t}=P_{t \mid t-1} H_{t}^{T}\left[H_{t} P_{t \mid t-1} H_{t}^{T}+R_{t}\right]^{-1} .
$$

The fourth step is to correct the one-step predicted state $\widehat{X}_{t \mid t-1}$ according to the principle of minimum error covariance and thus obtain the optimal estimation $\widehat{X}_{t \mid t}$ of the state

$$
\widehat{X}_{t \mid t}=\widehat{X}_{t \mid t-1}+K_{t}\left[Z_{t}-H_{t} \widehat{X}_{t \mid t-1}\right] .
$$

The fifth step is to compute the error covariance matrix $P_{t \mid t}$ of the updated state estimation $\widehat{X}_{t \mid t}$ :

$$
P_{t \mid t}=\left[I-K_{t} H_{t}\right] P_{t \mid t-1} .
$$




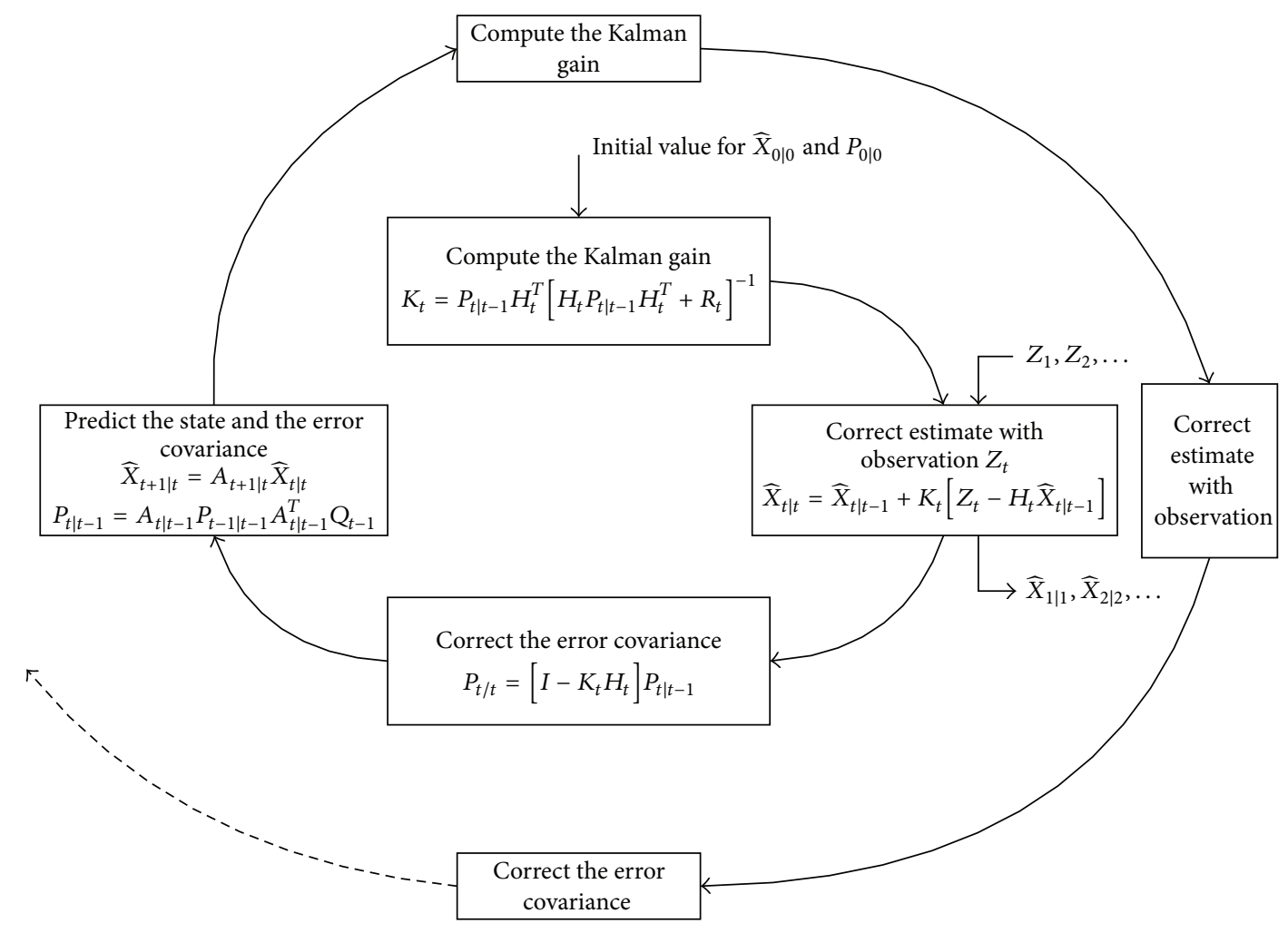

FIGURE 1: A complete picture of the operation of the Kalman filter.

These are the basic equations of Kalman filtering for a stochastic linear discrete system. The actual filtering process is an ongoing "predicting-correcting" process of a recursive nature. Figure 1 offers a complete picture of the operation of the Kalman filter.

The Kalman filter does not require storing large amounts of data in solving the problem. Once new data is observed, new filtering value can be calculated at any time. So this method facilitates real-time processing and is easy to implement on the computer.

\section{A Whole Process of Dynamic Prediction for Corporate Financial Distress}

As previously described, corporate financial distress is a gradual and cumulative process, which is developed from a healthy state. So the prediction should be long-term and continuous. And the continuously updated time-series data should be collected for the dynamic prediction, which could be the fresh input into the Kalman filter in order to obtain the optimal estimation closer to the actual state. The whole process of dynamic prediction for corporate financial distress is described as follows.

From Figure 2, we can see that if we want to predict the corporate financial state at time $t+2$, we just need to know the optimal estimation of the corporate financial state at time $t$ and the signal indicators observed at time $t+1$. The rest may be deduced by analogy; if we want to predict the corporate financial state at time $t+n$, we just need to know the optimal estimation of the corporate financial state at time $t+n-2$ and the signal indicators observed at time $t+n-1$. This continuous prediction does not require saving the observed data in the past. Every time the new signal indicators are observed, they are put into the Kalman filter as fresh. It helps solve the problems of storing, calling, and processing the massive data, thus greatly improving the speed of operation on the computer.

Further, if we want to predict the corporate financial state $n$-step ahead, we can obtain the $n$-step-ahead prediction algorithm deduced from the basic Kalman filter algorithm according to the dynamic prediction process described above.

The general $n$-step-ahead prediction algorithm is deduced as

$$
\begin{aligned}
\widehat{X}_{t+n \mid t} & =A_{t+n \mid t+n-1} A_{t+n-1 \mid t+n-2} \cdots A_{t+1 \mid t} \widehat{X}_{t \mid t} \\
& =\prod_{i=1}^{n} A_{t+i \mid t+i-1} \widehat{X}_{t \mid t} .
\end{aligned}
$$

The $n$-step-ahead prediction error variance matrix is

$$
\begin{aligned}
P_{t+n \mid t}= & \prod_{i=1}^{n} A_{t+i \mid t+i-1} P_{t \mid t} \prod_{i=1}^{n} A_{t+i \mid t+i-1}^{T} \\
& +\prod_{j=2}^{n} A_{t+j \mid t+j-1} Q_{t} \prod_{j=1}^{n} A_{t+j \mid t+j-1}^{T}+\cdots \\
& +A_{t+n \mid t+n-1} Q_{t+n-2} A_{t+n \mid t+n-1}^{T}+Q_{t+n-1} .
\end{aligned}
$$




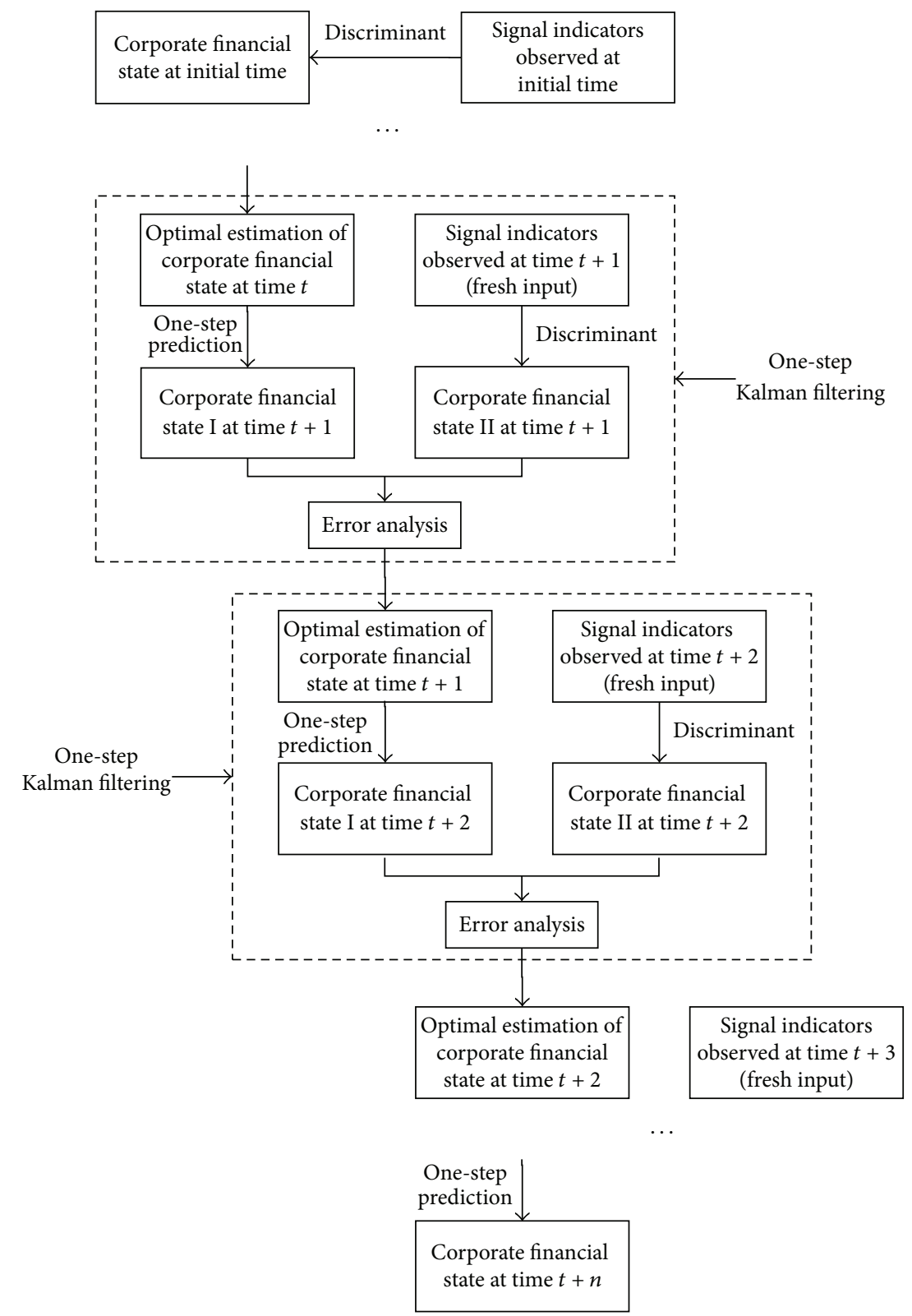

Figure 2: A whole process of dynamic prediction for corporate financial distress.

Assume that the system parameters $A_{t}$ and $Q_{t}$ have nothing to do with the time; then the above equations simplify to

$$
\begin{gathered}
\widehat{X}_{t+n \mid t}=A^{n} \widehat{X}_{t \mid t}, \\
P_{t+n \mid t}=A^{n} P_{t \mid t}\left(A^{T}\right)^{n}+A^{n-1} Q\left(A^{T}\right)^{n-1}+\cdots+A Q A^{T}+Q \\
=A^{n} P_{t \mid t}\left(A^{T}\right)^{n}+\sum_{j=2}^{n+1} A^{n+1-j} Q\left(A^{T}\right)^{n+1-j} .
\end{gathered}
$$

Based on (9) to (11), we could use data at shorter time interval to predict $n$-step ahead, but the prerequisite of sufficiently long-term data to find out the trend of development of the financial state should be satisfied.
In the dynamic prediction model for financial distress established in Section 2, we suppose that the financial state $X$ cannot be observed. But in reality, whether the company is trapped in financial distress each year is public information, so part of $X$ can be observed. We put this part of observed information into a likelihood equation in order to improve the accuracy of dynamic prediction. The probability of the company being trapped in financial distress is

$$
P\left(X_{t}>S_{c}\right)=\int_{S}^{\infty} p\left(x_{t}\right) d x_{t}
$$

where $S_{c}$ is the critical value, $x_{t+1}$ equals $e_{t+1}=x_{t+1}-$ $\widehat{x}_{t+1 \mid t}$, and the latter is normally distributed with mean 


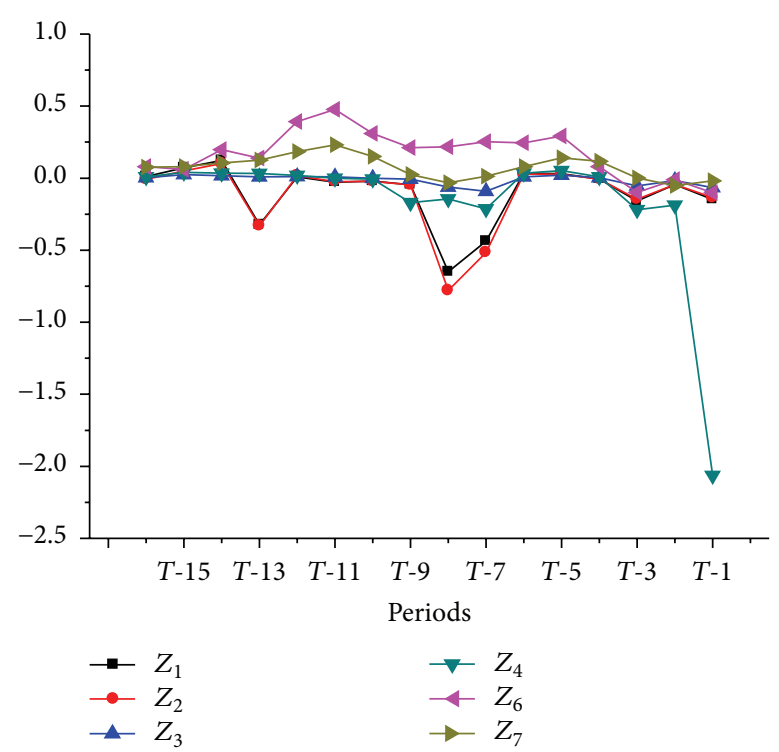

(a)

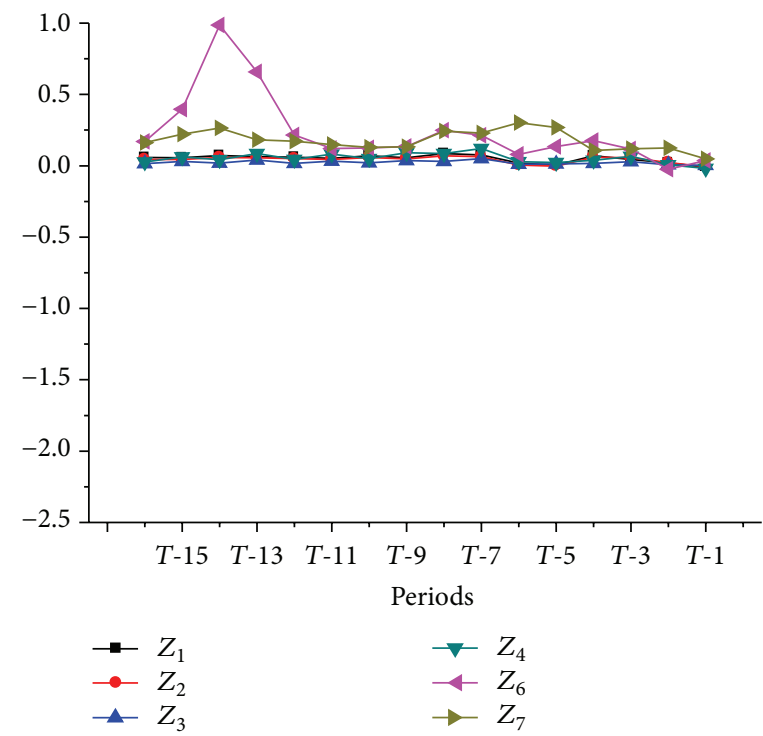

(b)

FIgURE 3: The trend analysis of mean of signal indicators of profitability for distress samples and healthy samples.

of 0 and variance of $F_{t+1}=H_{t+1} P_{t+1 \mid t} H_{t+1}^{T}+R_{t+1}$. Then

$$
p\left(x_{t}\right)=\frac{1}{P_{t} \sqrt{2 \pi}} e^{-(1 / 2)\left(\left(x_{t}-\widehat{x}_{t}\right) / P_{t}\right)} .
$$

If $M$ is the last year that $X$ can be observed, then the additional estimation equation is

$$
\begin{gathered}
l=-\frac{N M}{2} \lg (2 \pi)-\frac{1}{2} \sum_{t=1}^{M} \lg \left|F_{t}\right|-\frac{1}{2} \sum_{t=1}^{M} e_{t}^{T} F e_{t} \\
+\sum_{t=1}^{M}\left\{\lg \left[P\left(X_{t}>S_{c}\right)\right] \delta(t)\right. \\
\left.+\lg \left[P\left(X_{t}<S_{c}\right)\right][1-\delta(t)]\right\} .
\end{gathered}
$$

This additional estimation equation is used every year no matter if one year is divided into $n$ periods. When standing at managers' position, suppose we know the corporate financial state at time $t-1$ when we stay at time $t$. Then the additional estimation equation can be embedded in the general $n$-stepahead prediction algorithm every time to help improve the accuracy of dynamic prediction.

\section{Empirical Analysis}

4.1. Data Description and Experiment Design. Manufacturing industry is a major industry in China. "Made in China" has an important impact on the global economy. Therefore, prediction of corporate financial distress for China's manufacturing industry is of great significance. Generally, the manufacturing companies have complete production processes, equilibrious production cycle, and a more stable trend of development of the financial state. The characteristics of these companies can be well described using the existing financial indicators. And the dynamic prediction method described above can be put into practice for these manufacturing companies.

In this research, the data for our experiment are collected from the Shanghai Stock Exchange and Shenzhen Stock Exchange databases in China. ST (Special Treatment) companies because of financial problems are selected as distress samples; meanwhile companies of similar asset size which have never been special treated are selected as healthy samples. The ST time is treated as period T. For a six-month interval, the data eight years or sixteen periods before ST is selected as time-series sets for the distress samples. The time span of the paired samples is the same as the distress samples.

According to the above principles, the data of 152 listed companies is collected, and the time span is year 2002 to year 2009, year 2003 to year 2010, and year 2004 to year 2011, respectively. 60 ST companies and 60 paired companies of the first half of years 2010 and 2011 are treated as training set, which is used to derive the model. 16 ST companies and 16 paired companies of the first half of year 2012 are treated as testing set, which is used to test the effect of the model.

From the holistic perspective, we select 29 financial indicators covering four aspects of profitability, solvency, management efficiency, and market reaction as alternative signal indicators. The effect of the corporate financial problems may be amplified or reduced in information transmission mechanism of the market, and the problems may be exposed to the open market in advance or with a delay. If the problems are exposed in advance, the indicators can be used as a pilot signal of financial distress prediction, if delayed exposure, but also can be served as comprehensive evaluation of financial distress or the signal for the trend of development in the future. These are indicators of market reaction. The 29 signal indicators are listed in Table 1. 
TABLE 1: Comprehensive signal indicators of financial distress prediction.

\begin{tabular}{|c|c|c|}
\hline Type & Code & Signal indicators \\
\hline \multirow{7}{*}{ Profitability } & $Z_{1}$ & Operating profit margin \\
\hline & $Z_{2}$ & Net profit margin \\
\hline & $Z_{3}$ & Return on assets \\
\hline & $Z_{4}$ & Return on equity \\
\hline & $Z_{5}$ & Operating profit margin growth \\
\hline & $Z_{6}$ & Operating revenue growth \\
\hline & $Z_{7}$ & Total assets growth \\
\hline \multirow{7}{*}{ Solvency } & $Z_{8}$ & Current ratio \\
\hline & $Z_{9}$ & Quick ratio \\
\hline & $Z_{10}$ & Cash debt ratio \\
\hline & $Z_{11}$ & Debt coverage ratio \\
\hline & $Z_{12}$ & Interest coverage ratio \\
\hline & $Z_{13}$ & Liabilities to assets ratio \\
\hline & $Z_{14}$ & Liabilities to equity ratio \\
\hline \multirow{7}{*}{ Management efficiency } & $Z_{15}$ & Total assets turnover \\
\hline & $Z_{16}$ & Fixed asset turnover \\
\hline & $Z_{17}$ & Current assets turnover \\
\hline & $Z_{18}$ & Inventory turnover \\
\hline & $Z_{19}$ & Accounts receivable turnover \\
\hline & $Z_{20}$ & Cash ratio of main business \\
\hline & $Z_{21}$ & Cash return on assets \\
\hline \multirow{8}{*}{ Market reaction } & $Z_{22}$ & Earnings per share \\
\hline & $Z_{23}$ & Net assets per share \\
\hline & $Z_{24}$ & Operating revenue per share \\
\hline & $Z_{25}$ & Capital reserve per share \\
\hline & $Z_{26}$ & Retained earnings per share \\
\hline & $Z_{27}$ & Price to book ratio \\
\hline & $Z_{28}$ & Equity to invested capital ratio \\
\hline & $Z_{29}$ & Net cash flow per share \\
\hline
\end{tabular}

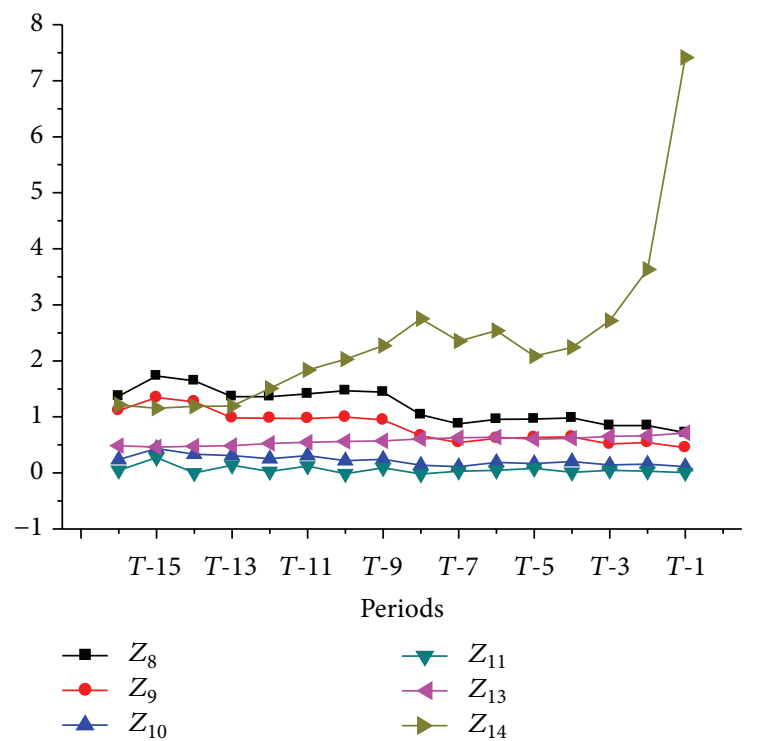

(a)

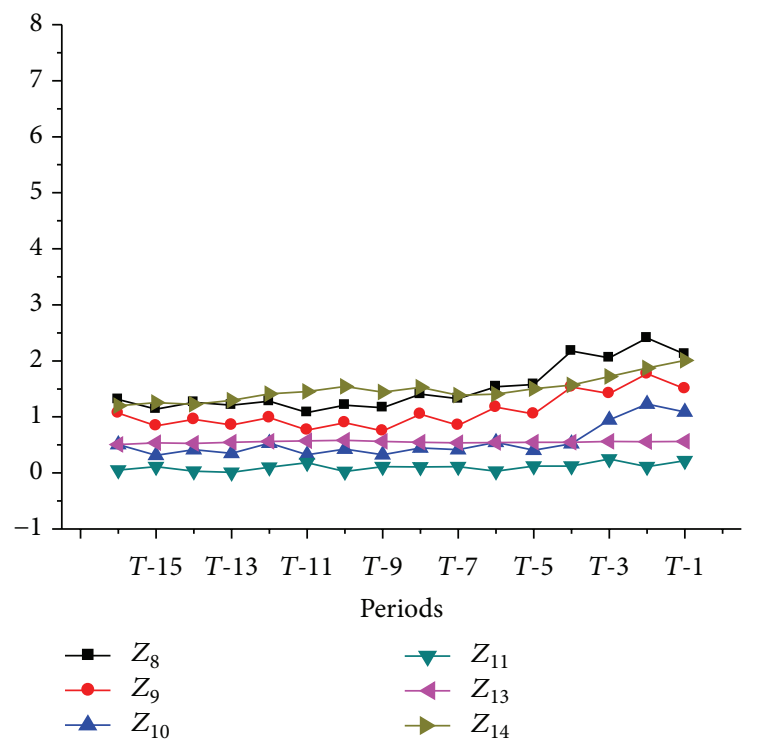

(b)

FIGURE 4: The trend analysis of mean of signal indicators of solvency for distress samples and healthy samples. 


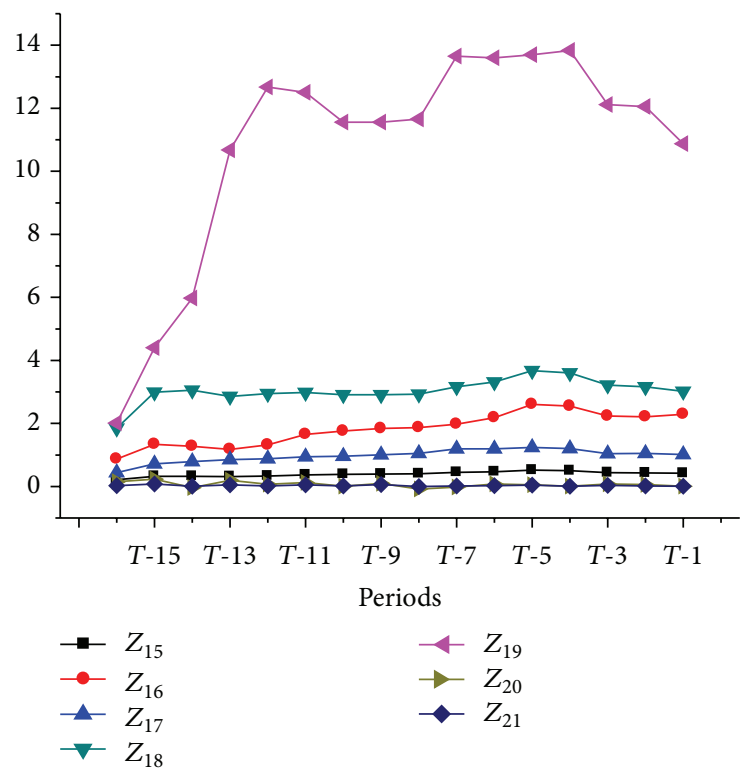

(a)

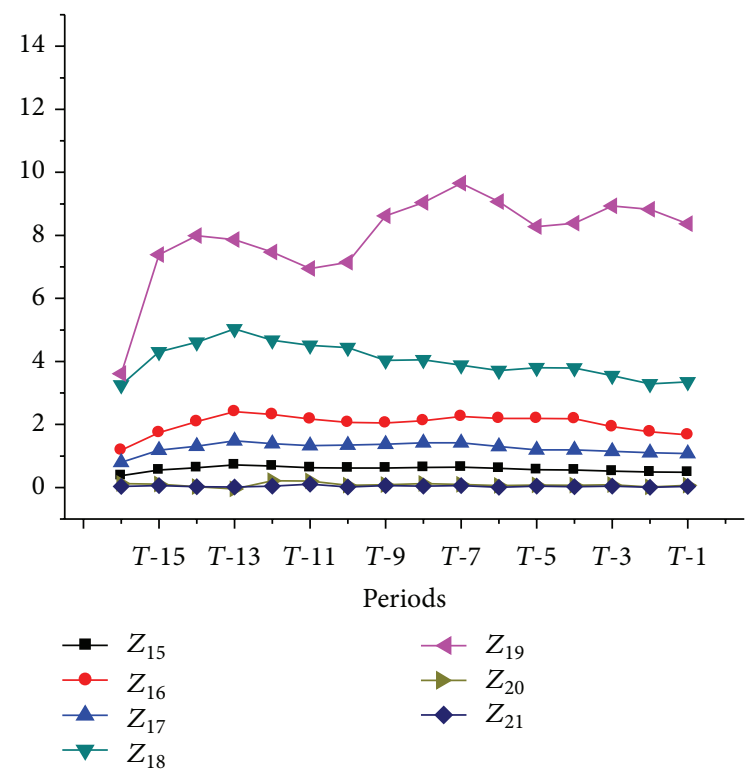

(b)

FIGURE 5: The trend analysis of mean of signal indicators of management efficiency for distress samples and healthy samples.

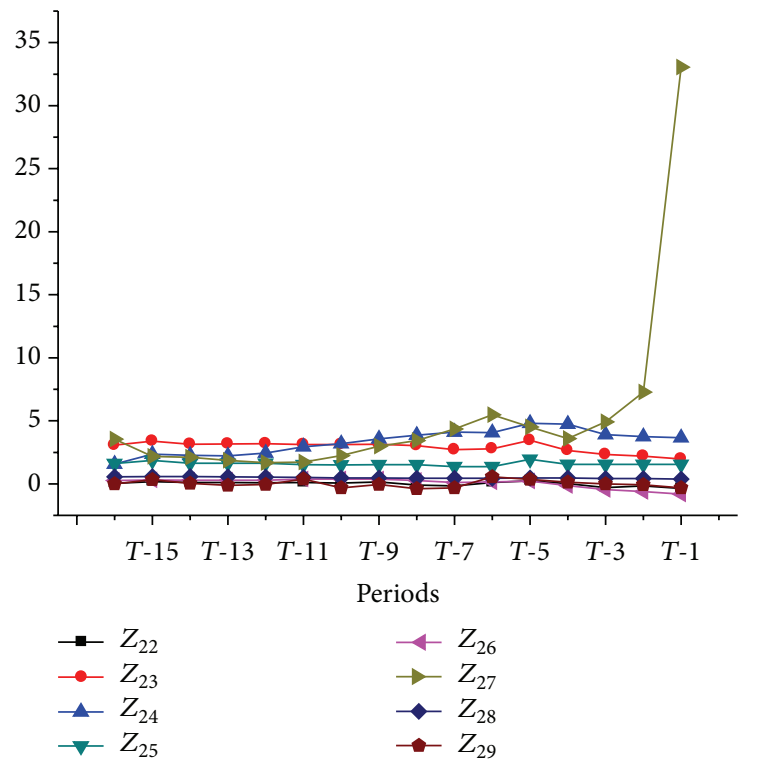

(a)

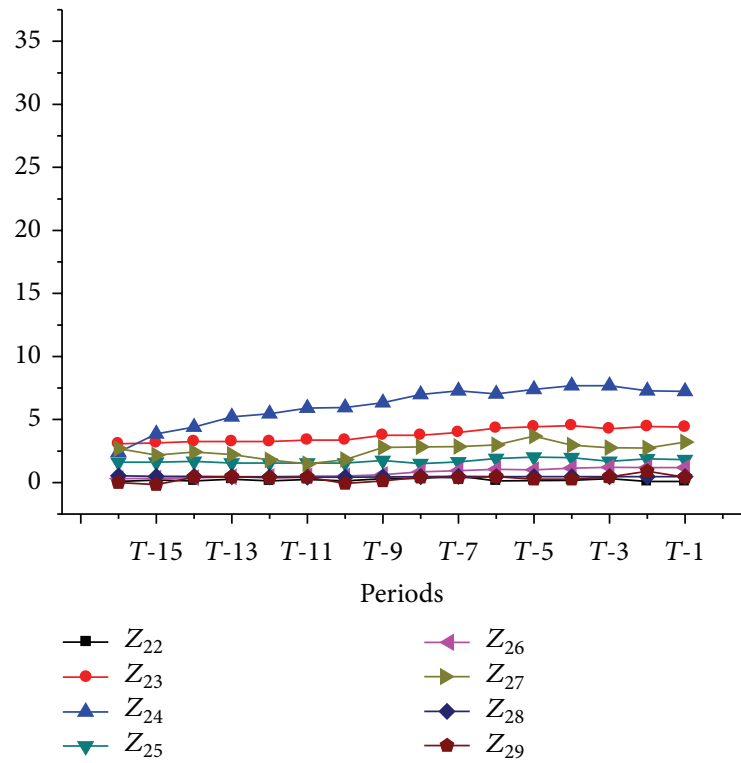

(b)

FIGURE 6: The trend analysis of mean of signal indicators of market reaction for distress samples and healthy samples.

A three-dimensional database is established consisting of 16 periods' time-series data of the above 152 sample enterprises, the financial state of which is represented by 27 signal indicators each. (As operating profit margin growth $\left(Z_{5}\right)$ and interest coverage ratio $\left(Z_{12}\right)$ have much missing data, we ignore these two subsets of the data, leaving the rest 27 subsets.) The dynamic prediction method described above is based on the trend of the time-series data. The trend analysis of signal indicators of profitability, solvency, management efficiency, and market reaction is shown in Figures 3-6. (Some indicators of management efficiency and market reaction show cyclical fluctuations, so we amend these indicators by smoothing. Figure 5 and Figure 6 have been amended.)

From Figures 3, 4, 5, and 6, we can see most indicators show a certain trend, which is the foundation of dynamic prediction.

Then we use nonparametric test of Mann-Whitney $U$ to find out when the difference between distress samples and healthy samples occurs. The results show that the gap between the two is maximized 2 years before ST time and the significant difference occurs 4 years before ST time. That 


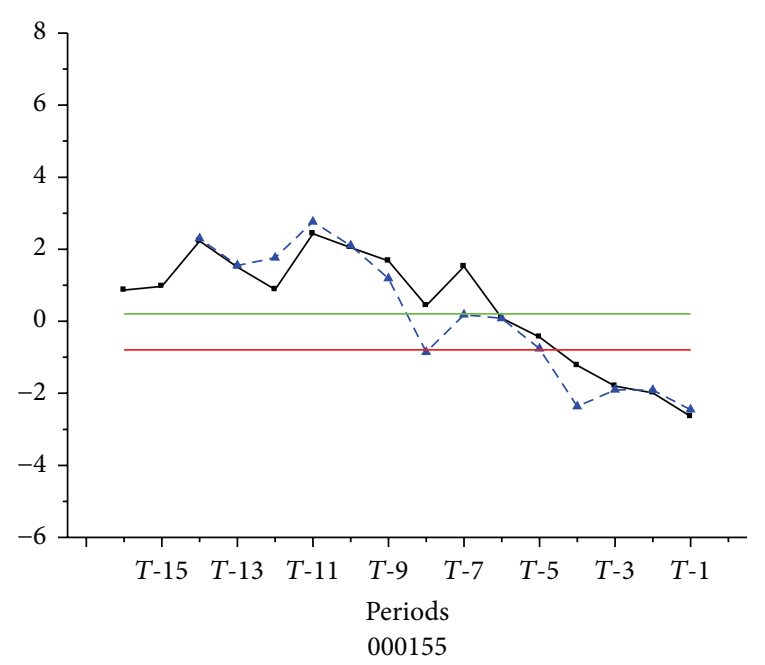

(a)

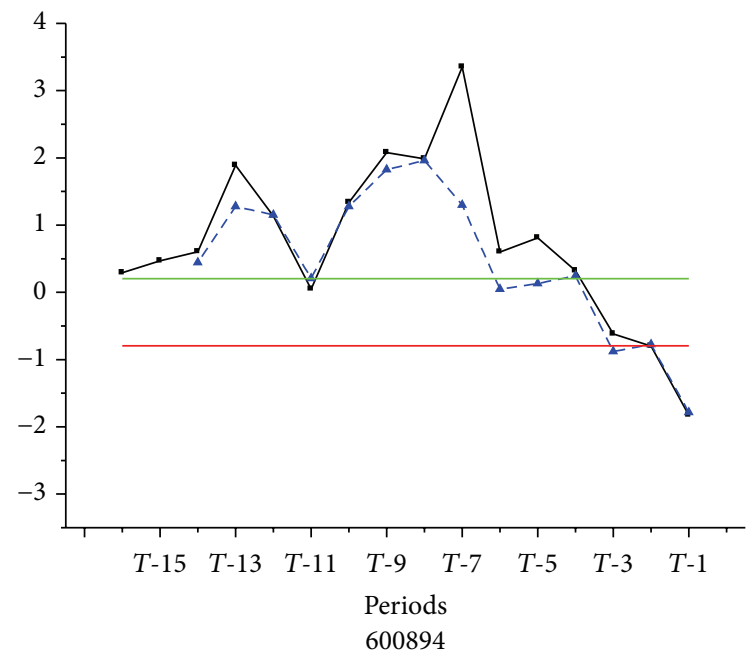

(c)

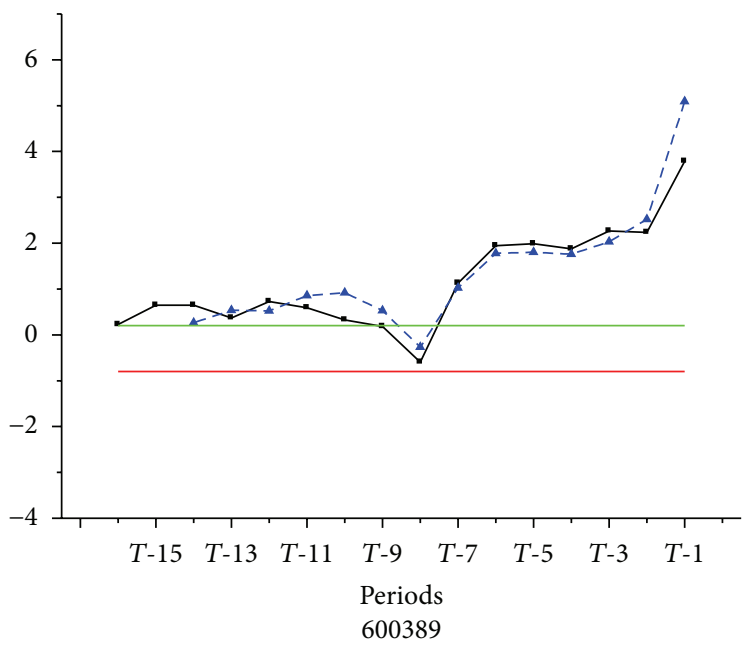

$\rightarrow$ Real

- - Prediction

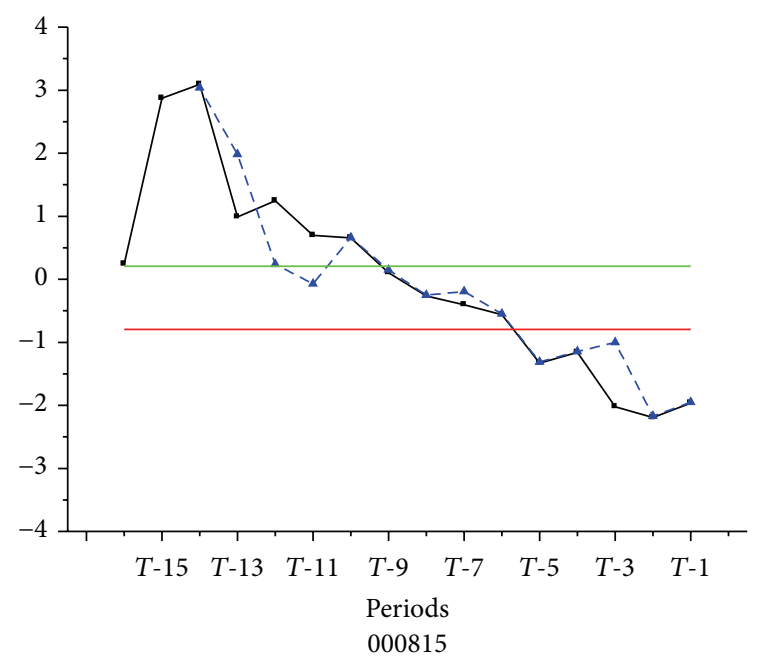

(b)

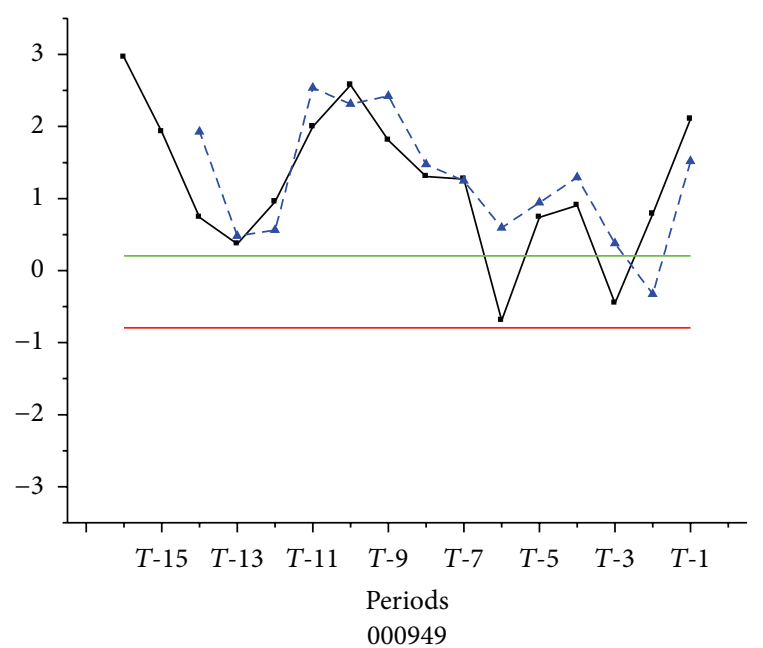

(d)

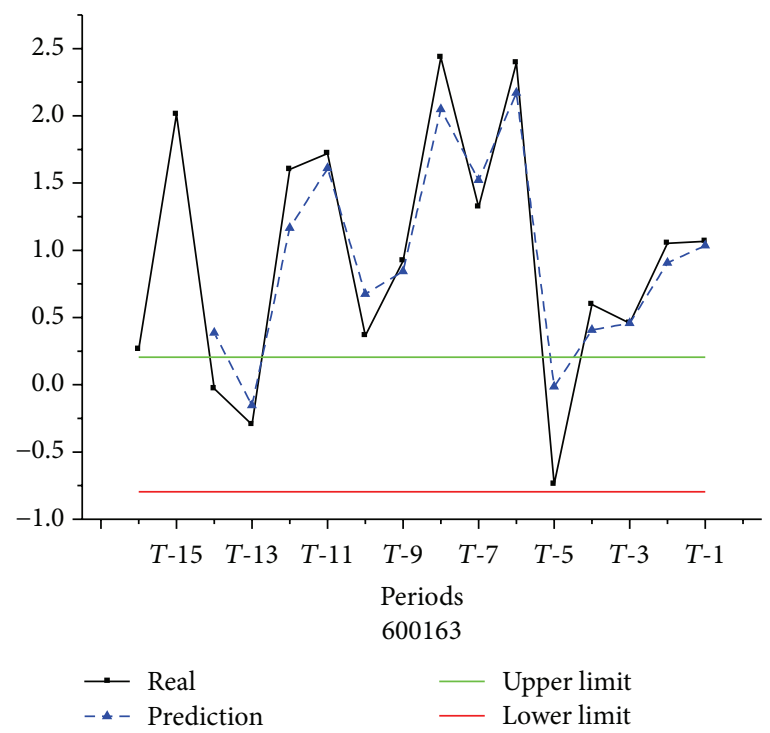

(f)

(e)

FIgURE 7: Dynamic prediction figures for part of testing samples. 
is, the earliest time to accurately predict the occurrence of financial distress should be 4 years before ST time.

4.2. Experiment Results and Analysis. We use principal component analysis to eliminate the effect of multicollinearity on the original variables. We extract first 10 principal components, and the accumulative contribution rate is above 92\% each for 152 companies. These principal components are linear combinations of the original signal indicators, which can be served as part of discriminant models for each company.

The parameters of process model are estimated from the data of training set. And also using the data of training set, the judgment for the threshold of financial distress is set as an interval which has lower and upper confidence limit.

The results show that the lower confidence limit is -0.796 and the upper confidence limit is 0.205 . When the predictive value of a company's financial state is lower than -0.796 , the company may fall into severe financial distress; when the predictive value is upper than 0.205 , the company is well operated; when the predictive value is between -0.796 and 0.205 , it is possible that the company is getting into financial distress.

Then we test the effect of the dynamic prediction model using the data of testing set. To space restrictions, we just list dynamic prediction figures for six companies, among which first three are ST companies, while the other three are non-ST companies. The company names and stock codes are Sichuan Chemical Company Limited (000155), MCC Meili Paper Industry Co., Ltd. (000815), Guangzhou Guangri Stock Co., Ltd. (600894), Xinxiang Chemical Fiber Co., Ltd. (000949), Nantong Jiangshan Agrochemical \& Chemicals Co., Ltd. (600389), and Nanzhi Co., Ltd., Fujian (600163), in turn. Dynamic prediction figures for these six companies are shown in Figure 7.

The testing results show that almost all of the curves of predictive value well fit the ones of real value for 32 testing samples.

Of 16 distress testing samples, 15 companies give mild alarm in period T-9 (4 years ahead). And 13 companies give severe alarm in period $T-7$ and period $T-5$ ( 3 years ahead and 2 years ahead). All of the 16 companies give severe alarm in period T-3 (1 year ahead). This shows that the information the dynamic model absorbed and produced almost covers the characteristics of financial distress. An accurate warning can be made four years before financial distress and the accuracy is $93.8 \%$. (We also take triple BPNN to make a comparison. The results show that the accuracy of prediction one year ahead to four years ahead is $100 \%, 93.8 \%, 62.5 \%$, and $43.8 \%$. The accuracy sharply declines three years ahead. It shows that the triple BPNN has better effect for short-term prediction rather than long-term prediction.)

For healthy testing samples, none is lower than the severe alarm limit. But sometimes the predictive values appear slightly below the mild alarm limit, showing that there have been cases of temporary deviation from healthy state for healthy testing samples. The dynamic model conducts a track and thereafter modifies. This shows that the model can objectively track and effectively predict the overall financial state of a company from a long run.

\section{Conclusions and Future Work}

In this paper, we focus on the dynamic nature of corporate financial distress and establish dynamic prediction models consisting of a process model and a discriminant model, which are used to describe the dynamic process and discriminant rules of financial distress, respectively. The operation of the dynamic prediction is achieved by Kalman filtering algorithm. And a general $n$-step-ahead prediction algorithm based on Kalman filter is deduced in order for prospective prediction. To validate the prediction performance of this method, we conduct an empirical study for China's manufacturing industry. The empirical results have proved the accuracy and advance of predicting financial distress using this dynamic model. The accuracy of prediction four years before financial distress is $93.8 \%$. In addition, this method also solves the problem of massive data processing as it does not require storing large amounts of historical data and thus can achieve real-time processing of data.

In this paper, we suppose the dynamic process of financial distress is linear. The Kalman filtering algorithm will be applied to a nonlinear dynamic model in the future research and it will offer a wider range of applications.

\section{Conflict of Interests}

The authors declare that there is no conflict of interests regarding the publication of this paper.

\section{Acknowledgments}

This research is supported by National Natural Science Foundation of China (Grant no. 71272111) and the Innovation Foundation of Jiangsu Province of China (Grant no. CXZZ12_0132).

\section{References}

[1] W. H. Beaver, "Financial ratios as predictors of failure," Journal of Accounting Research (Supplement), vol. 4, pp. 71-111, 1966.

[2] E. I. Altman, "Financial ratios, discriminant analysis and the prediction of corporate bankruptcy," The Journal of Finance, vol. 23, no. 4, pp. 589-609, 1968.

[3] E. I. Altman, R. G. Haldeman, and P. Narayanan, "ZETATM analysis: a new model to identify bankruptcy risk of corporations," Journal of Banking and Finance, vol. 1, no. 1, pp. 29-54, 1977.

[4] D. Martin, "Early warning of bank failure. A logit regression approach," Journal of Banking and Finance, vol. 1, no. 3, pp. 249276, 1977.

[5] J. A. Ohlson, "Financial ratios and the probabilistic prediction of bankruptcy," Journal of Accounting Research, vol. 18, no. 1, pp. 109-131, 1980.

[6] D. Wu, L. Liang, and Z. Yang, "Analyzing the financial distress of Chinese public companies using probabilistic neural networks 
and multivariate discriminate analysis," Socio-Economic Planning Sciences, vol. 42, no. 3, pp. 206-220, 2008.

[7] H. Shen, J. Cui, Z. Zhou, and H. Min, "BP-neural network model for financial risk warning in medicine listed company," in Proceedings of the 4th International Joint Conference on Computational Sciences and Optimization (CSO '11), pp. 767770, Yunnan, China, April 2011.

[8] X. Zhou, J. Y. Wang, W. Xie, and Y. Hong, "Research on the optimal methods of financial distress prediction based on BP neural networks," in Proceedings of the 2nd International Conference on Electric Information and Control Engineering, vol. 3, pp. 735-738, 2012.

[9] J. Sun, K. He, and H. Li, "SFFS-PC-NN optimized by genetic algorithm for dynamic prediction of financial distress with longitudinal data streams," Knowledge-Based Systems, vol. 24, no. 7, pp. 1013-1023, 2011.

[10] Y. Cao, G. Wan, and F. Wang, "Predicting financial distress of Chinese listed companies using rough set theory and support vector machine," Asia-Pacific Journal of Operational Research, vol. 28, no. 1, pp. 95-109, 2011.

[11] C. Park and I. Han, "A case-based reasoning with the feature weights derived by analytic hierarchy process for bankruptcy prediction," Expert Systems with Applications, vol. 23, no. 3, pp. 255-264, 2002.

[12] K. Shin, T. S. Lee, and H. Kim, "An application of support vector machines in bankruptcy prediction model," Expert Systems with Applications, vol. 28, no. 1, pp. 127-135, 2005.

[13] M. C. Lee and C. To, "Comparison of support vector machine and back propagation neural network in evaluating the enterprise financial distress," International Journal of Artificial Intelligence \& Applications, vol. 1, no. 3, pp. 31-43, 2010.

[14] A. Chaudhuri and K. De, "Fuzzy Support Vector Machine for bankruptcy prediction," Applied Soft Computing Journal, vol. 11, no. 2, pp. 2472-2486, 2011.

[15] E. I. Altman, G. Marco, and F. Varetto, "Corporate distress diagnosis: comparisons using linear discriminant analysis and neural networks," Journal of Banking and Finance, vol. 18, no. 3, pp. 505-529, 1994.

[16] F. Mokhatab Rafiei, S. M. Manzari, and S. Bostanian, "Financial health prediction models using artificial neural networks, genetic algorithm and multivariate discriminant analysis: Iranian evidence," Expert Systems with Applications, vol. 38, no. 8, pp. 10210-10217, 2011.

[17] E. Giovanis, "A study of panel logit model and adaptive neurofuzzy inference system in the prediction of financial distress periods," World Academy of Science, Engineering and Technology, vol. 64, pp. 646-652, 2010.

[18] P. Ravisankar and V. Ravi, "Financial distress prediction in banks using Group Method of Data Handling neural network, counter propagation neural network and fuzzy ARTMAP," Knowledge-Based Systems, vol. 23, no. 8, pp. 823-831, 2010.

[19] A. Bahrammirzaee, "A comparative survey of artificial intelligence applications in finance: artificial neural networks, expert system and hybrid intelligent systems," Neural Computing and Applications, vol. 19, no. 8, pp. 1165-1195, 2010.

[20] F. Tseng and Y. Hu, "Comparing four bankruptcy prediction models: logit, quadratic interval logit, neural and fuzzy neural networks," Expert Systems with Applications, vol. 37, no. 3, pp. 1846-1853, 2010.

[21] J. Sun and H. Li, "Dynamic financial distress prediction using instance selection for the disposal of concept drift," Expert Systems with Applications, vol. 38, no. 3, pp. 2566-2576, 2011.
[22] K. Konstantaras and C. Siriopoulos, "Estimating financial distress with a dynamic model: evidence from family owned enterprises in a small open economy," Journal of Multinational Financial Management, vol. 21, no. 4, pp. 239-255, 2011.

[23] E. Giarda, "Persistency of financial distress amongst Italian households: evidence from dynamic models for binary panel data," Journal of Banking and Finance, vol. 37, no. 9, pp. 34253434, 2013.

[24] J. Durbin and S. J. Koopman, Time Series Analysis by State Space Methods, Oxford University Press, Oxford, UK, 2nd edition, 2012.

[25] R. E. Kalman, "A new approach to linear filtering and prediction problems," Journal of Basic Engineering, vol. 82, pp. 35-45, 1960.

[26] R. G. Brown and P. Y. C. Hwang, Introduction to Random Signals and Applied Kalman Filtering, John Wiley \& Sons, New York, NY, USA, 3rd edition, 1997.

[27] T. Arnold, M. J. Bertus, and J. Godbey, "A simplified approach to understanding the Kalman filter technique," Engineering Economist, vol. 53, no. 2, pp. 140-155, 2008.

[28] Y. Shi and H. Fang, "Kalman filter-based identification for systems with randomly missing measurements in a network environment," International Journal of Control, vol. 83, no. 3, pp. 538-551, 2010. 


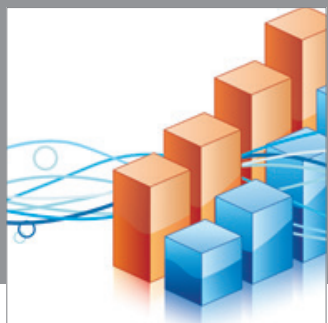

Advances in

Operations Research

mansans

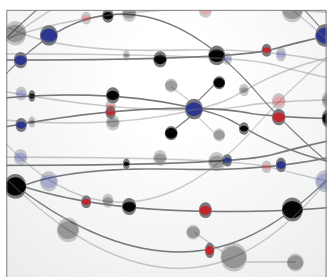

The Scientific World Journal
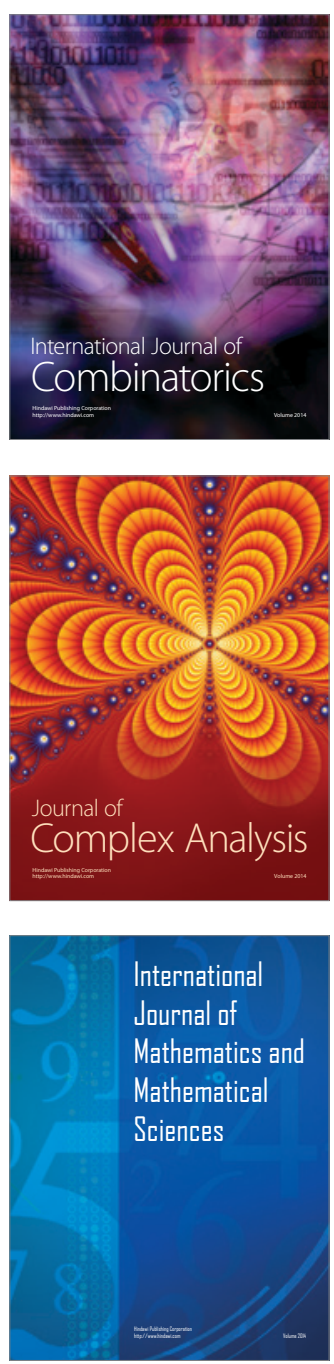
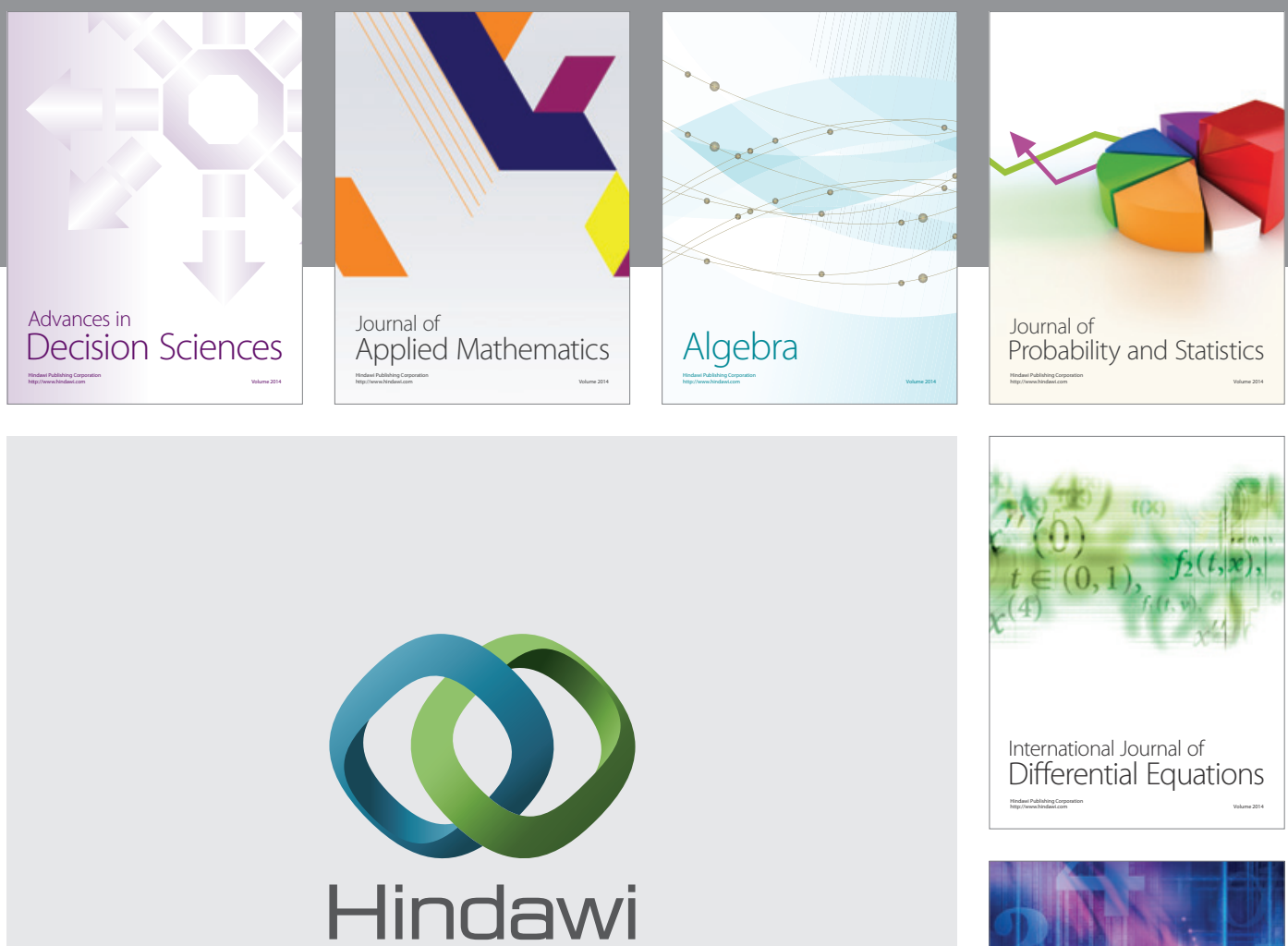

Submit your manuscripts at http://www.hindawi.com
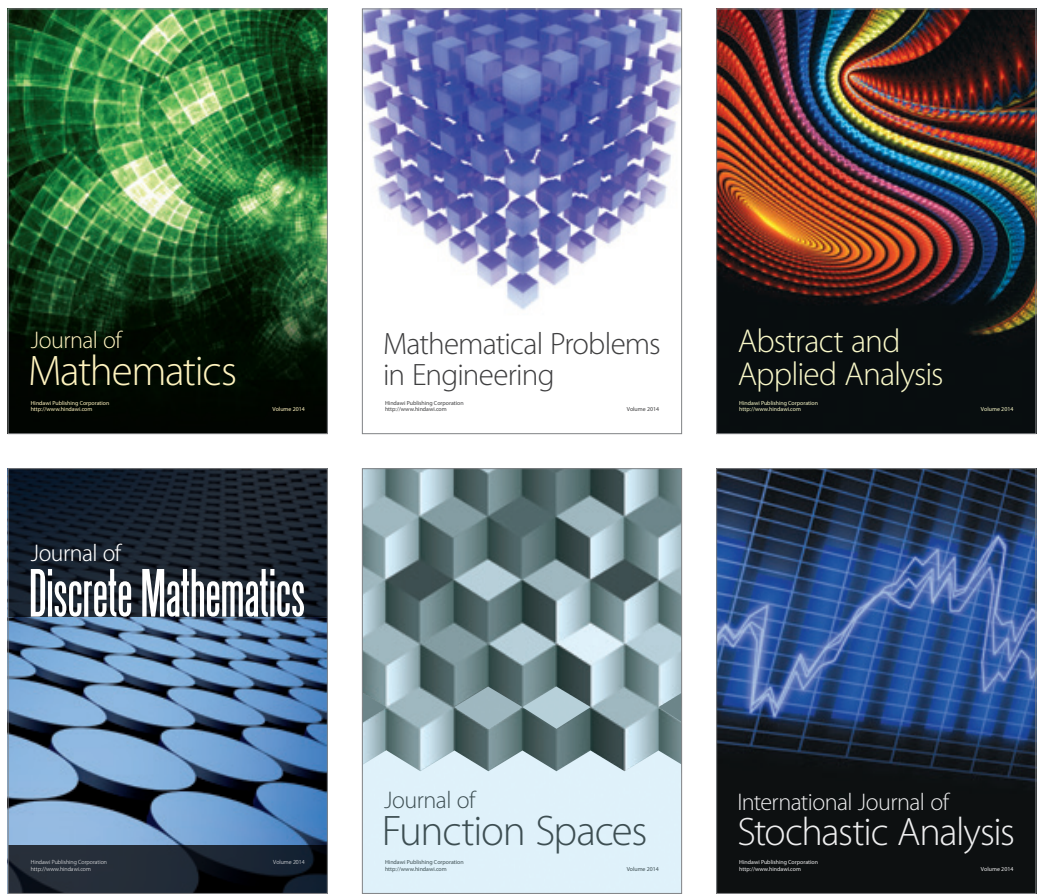

Journal of

Function Spaces

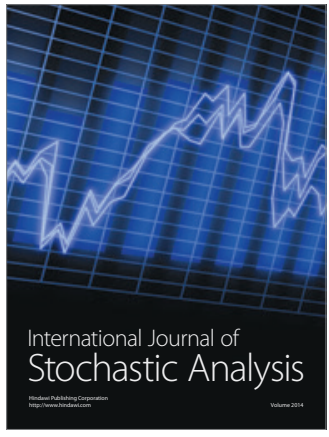

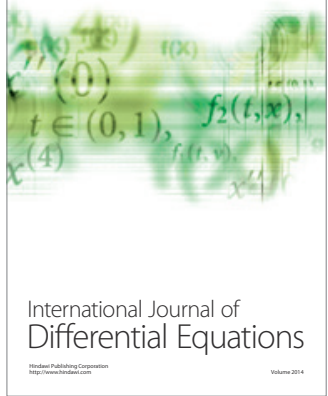
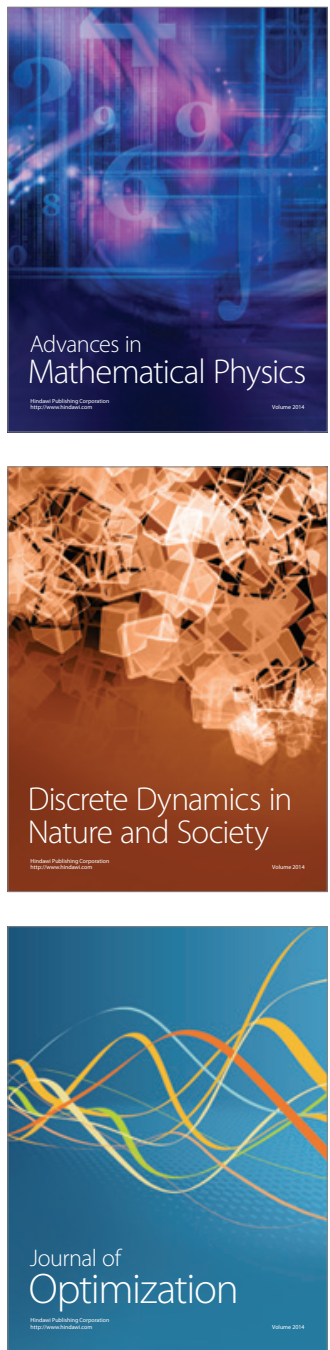